\section{DE DE GRUYTER} OPEN
Journal of Intercultural Management

Vol. 5, No. 3, September 2013, pp. 39-47

DOI 10.2478/joim-2013-0017

Barbara Mazur

Politechnika Białostocka

\title{
Linking diversity management and corporate social responsibility
}

\begin{abstract}
Abstrac: Corporate Social Responsibility (CSR) is a complex concept which embraces three organizational logics: economical, social and environmental. ADAMPOL, a Polish firm operating in Podlasie region, serves as an example of a company which declares in its documents (like the CSR report) that it has balanced CSR logics. The study contributes with insights to the organizational management of potentially opposing logics in CSR. Managing contradictions of CSR is an ongoing challenge and accomplishment influencing whether ethical, social and business logics collide or reinforce each other. The study shows - on the basis of research findings of a Danish frontrunner firm DanCo - that when ethics are framed as means to economic ends, some social responsibilities have a tendency to be disregarded in practice.
\end{abstract}

Keywords: Corporate social responsibility, logics of responsible management, diversity

\section{Introduction}

The aim of CSR is to analyze the interdependent relationships that exist between corporations and economic systems, ecosystems and the societies. The main objectives of this study are: firstly-presenting the conception of CSR from three different perspectives (economical, social and environmental) with main focus on social logics expressed by diversity management of the employees, secondly - showing potential relations among presented logics in the light of organizational theory, and thirdly-presenting the relations between social and economic logics of CSR in one of frontrunner Danish corporation. The scope of the study embraces the management of multiple institutional logics. The method is reviewing the literature in English on CSR and multiple, pluralistic 
institutional logics and presenting some results of the case study research conducted by the researchers of The Aarhus University on contradictions of corporate social responsibility.

A good number of articles, books, periodicals and papers dedicated to CSR have been published so far. Majority of them discuss different aspects of CSR and present particular actions taken by companies in the frame of the CSR concept. These actions - being in many cases treated as promotional or having in purpose creating a good image - have been usually presented in a way which was not linked with the overall institutional objectives.

\section{Management of the institutional logics}

According to the institutional theory's approach, institutions have a central logic. P.H.Thornton and W.Ocasio [1999, p. 804] defined institutional logics as the socially constructed, historical patterns of material practices, assumptions, values, beliefs, and rules by which individuals produce and reproduce their material subsistence, organize time and space, and provide meaning to their social reality. According to this definition institutionallogics provide alink between individual agency and cognition and socially constructed institutional practices and rule structures. This approach to institutional logics integrates the structural, normative, and symbolic as three necessary and complementary dimensions of institutions. In more practical terms institutional logics are means-end relationships [Boxenbaum E., 2006], that is actions that are considered appropriate to achieve given goals. Coexisting logics can both be opposing and reinforcing, marginalized and submerged. Institutional pluralism is thus a source of coexisting, potentially contradictory logics [Thornton P.H, Ocasio W., 2008]. CSR involves ethical, social and business logics, which can be both reinforcing and conflicting depending on how they are managed and combined in everyday practice or on the character of the institutional environments.

Organizations embedded in environments with conflicts in institutional prescriptions are likely to experience institutional contradictions on an ongoing basis within their everyday working practices, policies and strategies [Pache A.C., Santos F., 2010]. Hence, managing institutional contradictions may in such cases constitute an ongoing organizational challenge and accomplishment. Institutional paradoxes are manifested as potential tensions within everyday interactions of organizational actors as well as in the organizations' interaction with their surroundings. One strategy employed to handle coexisting, yet opposing logics is to separate or 'decouple' formal organizational form from actual practice [Boxenbaum E., Jonsson S., 2008]. Institutional contradictions may potentially threaten organizational coherence and constitute a source of instability, tensions and fragmentation [Kraatz M.S., Block E.S., 2008]. In this way all organizations in heterogeneous environments are compelled to find 
ways to manage, exploit or resolve the institutional contradictions in which they are embedded by combining or separating, furthering or submerging institutional logics within their work practices, programs and policies.

\section{CSR - social, economical and environmental logics}

The conception of corporate social responsibility which seems to be quite modern goes back to the previous times. As early as in the $18^{\text {th }}$ century companies have acted in a socially responsible manner by building houses and schools for their employees and their children. Since the mid of the 1990s political and public debates about social responsibilities of firms have gained renewed force. This development reflects a broader trend to see business and society as interwoven.

Corporate social responsibly is the continuing commitment by business to behave according to the business ethics and contribute to the economic development while improving the quality of life of workforce and their families as well as local community and society at large. CSR is a process with the aim to embrace responsibility for the company's actions and encourage a positive impact through its activities on the environment, consumers, employees, communities and stakeholders. The purpose of CSR is to make corporate business activity and corporate culture sustainable in three logics: economic, social and environmental .

Economical logics of CSR consist of understanding the economic impacts of the company's operations. Economic issues have long been overlooked in the discussion on corporate social responsibility. For many years, the aspect has been widely assumed to be well managed. However, it is actually the least understood and underrepresented by many of those shaping the corporate and public policy agendas. The economic aspects is often mistakenly considered to be synonymous with financial issues. However, the economic responsibility is not simply a matter of companies being financially accountable, recording employment figures and debts in their latest corporate responsibility report. The economic dimension of the sustainability agenda should rather consider the direct and indirect economic impacts that the organization's operations have on the surrounding community and on the company's stakeholders. That is what makes up corporate economic responsibility [Uddin M.B., Hassan M.R., Tarique K.M., 2008, pp.204-205].

Social logics of CSR is the newest of the three dimensions of corporate social responsibility and it is getting more attention than it has previously had. Many organizations are becoming increasingly active in addressing social concerns social responsibility means being accountable for the social effects the company has on people - even indirectly. This includes people within the company, in the supply chain of the company, in the community the company 
is in and as customers of the company which means the stakeholders. It refers to the management's obligation to make choices and take actions that will contribute to the well fare and interests of the society as well as those of the organization [Uddin M.B., Hassan M.R., Tarique K.M., 2008, pp.205-206].

Environmental logics of $\boldsymbol{C S R}$ is a key pillar of the corporate social responsibility. Environmental and ecological issues have been an important topic of discussion for the past thirty years in the business world - the longest time of the three dimensions corporate social responsibility. The knowledge and issues within the dimensions have progressed across a landscape of changing business realities. Environmental aspects put in place in the 1970s with the first real understanding of the environmental impacts of business [Uddin M.B.,, Hassan M.R., Tarique K.M., 2008, pp.206-208].

Organizations must balance multiple, potentially opposing logics of CSR as an ongoing accomplishment in their intra organizational interactions as well as in interactions with their external environment.

\section{Managing diversity as a social logics}

Research on CSR issues focuses mainly on economic and environmental issues. Therefore corporate social responsibility is not a threat to the achievement of economic goals of a corporation; CSR is rather an opportunity and can be the basis of economic development of firms in terms of competitive advantage in the global market. When dealing with the social aspect of CSR, most works focus on philanthropy and volunteering - activities that might contribute to the reputation and public relations, but are not viewed as core business practices. Majority of managers, even those managing CSR and diversity, don't always see the connection between the social aspect of CSR and responsibility for people. Good governance and reputation management are no longer optional for organizations of any size and with that now also comes the management of business practices such as CSR and diversity. Shareholders require companies to behave responsibly and ethically, and companies need to understand how giving back to the community is critical to both the bottom line and to the growth and health of their workforce. Managing CSR should mean managing diversity of the employees. It should embrace diversity of the employees which is in the frame of it. What are the corporate social responsibility issues that need to be managed by organizations which have diverse employees in the workplace? Those organizations need to reply to the following questions:

- Does the company respect all current and potential employees by valuing them for themselves, and avoiding placing artificial barriers or distinctions based on any aspect of the differences between them?

- Does the company apply basic minimum standards - the respect for human rights and dignity - in all countries where it operates and does business? 
Although local working conditions may vary depending on the culture and practice of the country concerned, do the core values still apply in how the company responds to these?

Managing diversity is considered to have been one of the most popular HRM strategies of the 1990s, and has since become widely accepted as an important and powerful management tool [Mazur B., 2009, p. 55]. Literature on diversity management emphasizes its two-fold purpose: to identify and correct discriminatory practices in the workplace and to help organizations gain a competitive advantage through the positive effects of diversity on a team and organizational performance. Diversity can make teams more innovative and flexible and in that way increase their productivity, which can in turn be translated into increased overall organizational performance [Cox T., Blake S., 1991, p.47].

Diversity management positively values difference and thus provides a radically new approach to the question of the "different" at work. Managing diversity seems to be a proactive strategy with the aim of maximizing the utilization of employees' potential [Mazur B., 2009, p.56]. The literature on diversity management suggests several economic advantages of diversifying the workforce [Cox T., Blake S., 1991, p. 47]. These advantages include a better understanding of local markets and customers, increased ability to attract and to retain the best people, greater creativity, better problem-solving abilities and greater flexibility. Another argument is that valuing differences enhances people's impression that they are valued for what they are, which in turn leads to higher productivity. These arguments suggest that the diversity perspective justifies the integration of minority groups more on the grounds of economic rather than legal or social reasons.

\section{CSR logics as potentially reinforcing}

It has been already said that CSR involves ethical, social and business logics, which can be both reinforcing and conflicting depending on how they are managed and combined in everyday practice. Nowadays many organizations declare successfully managing all CSR logics. They undertake the effective actions in the arena of environmental, social and economic responsibilities. Such actions seem to reinforce each other creating an image of sustainable managing of CSR logics.

ADAMPOL SA - a small firm which operates in the field of international and domestic car transport might serve as an example of such reinforcing CSR logics management. It is situated near Bialystok, the capital city of the Podlasie Voivodship (Poland). Multinational character of the region provided solid background for the creation of distinct systems of values and attitudes, 
characteristic of representatives of different denominations inhabiting the north-east of Poland. The employees represent mainly two Christian denominations - Catholic and Orthodox - coexisting for centuries in the Podlasie region. For this reason it seemed to be an obvious choice for studying the CSR and diversity management issues. ADAMPOL SA is a business which is continuously learning and applying this knowledge to best management practices of corporate social responsibility management.

In 2012 ADAMPOL SA, a member of UN Global Compact, presented the second report on CSR which shows, the economic, environmental, and social aspects of the company's operations in 2011. Providing innovative technological solutions to customers, the ethical activities of its employees, and a gradual introduction of a green office by limiting the consumption of paper, energy, and water are only some of the activities being undertaken by ADAMPOL SA which belong to the scope of CSR.

For the company, CSR means the implementation of a management strategy in which the company is a participant in community life: if we wish to achieve market success, we always need to consider the good of our environment. ADAMPOL $S A$ has been respecting the social responsibility principles in its business concept for many years and requires the same from its stakeholders: it supports those customers who heed the ethical aspects of offered goods and services, and those who care about ecology and presenting a good image.

The CSR team in ADAMPOL SA is responsible for all CSR activities, as well as coordinating the CSR reporting process at the company. All stakeholders may contact this team at: csr@adampolsa.com.pl.

In regard to managing diversity of the employees as a CSR social logics symptom the Vice-president of ADAMPOL SA, when interviewed, agreed that the region is vividly ethnically diverse and he agreed also that without knowing the religion you are not able to understand the employees of the Podlasie region. In his opinion each group represents unique mentality. He also confirmed that he noticed different ways of thinking of both groups of their employees in the workplace. He added that the pluralism of denominations and religions requires knowledge to enable better understanding of all employees at work. Such knowledge is also very useful for a better organizing of the work process which leads to success on the market. He also added: Managers should know religious backgrounds of the employees because due to different Christmas and Easter terms they are able to make the work process fluent. Mysticism and rites are more important for Orthodox believers than for Catholics and it should be respected. Orthodox are valuable in our firm because they speak Russian and many of them speak English as well. Therefore, they are irreplaceable in business trips both to the West or East. They have no problems when communicating. 


\section{Economic and social logics as opposing in practice}

Danish society constitutes a specific sociocultural context for diversity management [Boxenbaum 2006]. During the past two decades, the impact of migrants on Danish society and policies has been a significant issue. For illustrating in what way the CSR logics actually coexist in an organization, the research of one of Denmark's largest and most successful corporations with a solid reputation for CSR engagement was undertaken by two Danish researchers representing Aarhus University [Bjerregaard T., Lauring J., 2013]. They have noticed that the company's Web page DanCo states that Social responsibility is more than a virtue-it is a business imperative. Accordingly, the DanCo management discursively associated CSR with economic, social and ethical logics of doing business. They have also assumed that in this line of thinking CSR was linked to the ability to balance the potentially opposing logics of business and ethics. It was stated that the CSR program was targeted at increasing the employment of talented minority-group members. As explained to one of the researchers by a top manager: We want to attract and retain qualified employees. That means extending the pool of potential employees to ensure that we use all of the available resources in our increasingly diverse society' [BjerregaardT., Lauring J, 2013]. A similar statement was expressed on the Web page: We need to recruit the best people and provide them with equal opportunities to develop and apply their skills. Accordingly, the ideal of being a socially responsible corporation was closely linked to business strategies.

The department from which they collected data was a business unit dealing with international marketing. This setting provided interesting examples of some of the institutional contradictions inherent in managing CSR: for example when ethics was formally formulated as being economically viable, then some social responsibilities might have a tendency to be disregarded in practice. Hence, social logics might then be submerged by the business logic in the ongoing management of the pluralistic CSR logics [BjerregaardT., Lauring J., 2013].

They used different tools when conducting the DanCo research: participants observations, interviews, and documents. The findings of their research showed the contradictions of CSR logics. The management of the department expressed a need for ethnic and cultural diversity to facilitate strategies of international product promotion, pricing, planning of international conferences, sales and market analysis. This meant that, apart from dedication to the logic of social responsibility, the business (economic) logic was strongly present in the recruitment of foreign nationals. As it was stated in a departmental management presentation: Our employees come from many countries and many cultures, speaking many languages, with many different professional backgrounds. 
Only when we treat all of our employees with respect can we take advantage of the unique and diverse talents that they bring. And only when we treat our employees with dignity can we attract and keep the very best talent [Bjerregaard T., Lauring J., 2013]. Hence, Human Resource (HR) officials and managers were expected to focus on the professional qualifications needed in the different teams in line with the business logic, while simultaneously considering equal opportunities maintaining the ethnic or gender-wise balance in accord with the social logic of CSR. Although it was an important element in the official corporate policy, debating CSR was perceived to be unnecessary. While the general opinion was that equal opportunity policies were not necessary, a number of individuals noted that very few employees really stood out from the crowd. With the exception of a small group of Chinese employees, foreigners generally came from Europe or North America, and very few were dark-skinned or dressed differently. This made some managers consider the possibility that recruitment practices maybe had developed to "mirror ourselves". Or as a Danish team member argued: We claim that we are open, but, anyways, there are some countries and some colors we are not entirely open towards [Bjerregaard T., Lauring J., 2013]. Accordingly, the practice of including diversity had to balance an efficiency logic and a social responsibility logic with practical implications for the demographic composition of department members. Yet, the two coexisting, potentially opposing logics were managed in the actual practice of HR work by submerging the social logic to the business logic. Rather than embracing both logics simultaneously, the management of the opposing logics was in practice achieved by attending to the business side of the institutional oppositions. In consequence, on a practical level business logics seemed to submerge ethical logics. This way of managing coexisting logics also prevented actual employee diversity.

\section{Conclusions}

As presented DanCo study proves, it happens that the company in the sphere of declarations and documentation refers to the concept of CSR, being convinced that it realizes it, while in the management practice business logic prevails, placing the realization of economic objectives of the company in the first place. This demonstrates the need for a systematic study of relations between various logics, especially social and economical ones, in business management. This would allow, in the supremacy of one of them, to take action to balance the different logics of CSR in the organization. Only then it will be possible to develop such a comprehensive institutional logic which would balance the responsibility of the company in the social and economic area in the place of the domination of the business logic. A systematic audit would be a mean for achieving this goal. As for the other company - ADAMPOL SA - it 
seems necessary to conduct a more detailed study, similar in form and content to a Danish company, as only that would allow a final confirmation of balance of CSR logics in its activities. Conducting a study of employees of different levels and different faiths seems to be the most important in this case. Only then will it be possible to put a definitive diagnosis of the relationship - supporting or weakening - the CSR activities in the studied company.

\section{Bibliography}

Bjerregaard T., Lauring J., (2013), 'Managing contradictions of corporate social responsibility: the sustainability of diversity in a frontrunner firm', Business Ethics: An European Review, vol22, no2, April, pp.131-142

Boxenbaum, E. (2006), 'Lost in translation? The making of Danish diversity management', American Behavioral Scientist, vol. 49, no7, pp. 939-948.

Boxenbaum, E., Jonsson, S. (2008), 'Isomorphism, diffusion and decoupling', in Greenwood, R., Oliver, C., Sahlin, K., Suddaby, R. (ed.), The SAGE Handbook of Organizational Institutionalism, London: Sage.

Cox T., Blake S., (1991), 'Managing Cultural Diversity: Implications for Organizational Competitiveness', Academy of Management Executive, vol 3, no 5 , pp.45-56.

Den Hond F., De Bakker F. G. A, Neergaad P.,(2007), Managing Corporate Social Responsibility in Action: Talking, Doing and Measuring, Ashgate, Hamshire.

Kraatz, M.S., Block, E.S., (2008), 'Organizational implications of institutional pluralism', in Greenwood, R., Oliver, C., Sahlin, K., and Suddaby, R. (ed.), The SAGE Handbook of Organizational Institutionalis, London, Sage.

Mazur B., (2009), Zarządzanie w warunkach różnorodności zasobów ludzkich, Białystok, WSFiZ w Białymstoku.

Pache, A.C., Santos, F., (2010), When worlds collide: the internal dynamics of organizational responses to conflicting institutional demands, "Academy of Management Review", vol. 35(3), pp. 455-476.

Thornton, P., Ocasio W., (1999), Institutional Logics and the Historical Contingency of Power in Organizations: Executive Succession in the Higher Education Publishing Industry, 1958-1990, „American Journal of Sociology”, vol. 105 (3), pp. 801-843.

Thornton, P.H., Ocasio, W. (2008), Institutional logics, [in:] In Greenwood, R., Oliver, C., Sahlin, K. Suddaby, R. (eds.), The SAGE Handbook of Organizational Institutionalism, Sage, London.

Uddin M. B., Hassan M. R.,. Tarique K.M.,( 2008), Three Dimensional Aspects of Corporate Social Responsibility, „Daffodil International University Journal of Business and Economics", Vol. 3, (1), pp. 199-212. 